NBER WORKING PAPER SERIES

\title{
CAN ENDOGENOUS CHANGES IN PRICE FLEXIBILITY ALTER THE RELATIVE WELFARE PERFORMANCE OF EXCHANGE RATE REGIMES?
}

\author{
Ozge Senay \\ Alan Sutherland \\ Working Paper 11092 \\ http://www.nber.org/papers/w11092
NATIONAL BUREAU OF ECONOMIC RESEARCH
1050 Massachusetts Avenue
Cambridge, MA 02138
January 2005

This is a revised version of "Endogenous Price Flexibility, the Expenditure Switching Effect and Exchange Rate Regime Choice" which was presented at the NBER International Seminar on Macroeconomics, Reykjavik, Iceland, June 18-19, 2004. The views expressed herein are those of the author(s) and do not necessarily reflect the views of the National Bureau of Economic Research.

(C) 2005 by Ozge Senay and Alan Sutherland. All rights reserved. Short sections of text, not to exceed two paragraphs, may be quoted without explicit permission provided that full credit, including $\odot$ notice, is given to the source. 
Can Endogenous Changes in Price Flexibility Alter the Relative Welfare Performance of Exchange Rate Regimes?

Ozge Senay and Alan Sutherland

NBER Working Paper No. 11092

January 2005

JEL No. E52, F41, F42

\section{$\underline{\text { ABSTRACT }}$}

A dynamic general equilibrium model of a small open economy is presented where agents may choose the frequency of price changes. A fixed exchange rate is compared to inflation targeting and money targeting. A fixed rate generates more price flexibility than the other regimes when the expenditure switching effect is relatively weak, while money targeting generates more flexibility when the expenditure switching effect is strong. These endogenous changes in price flexibility can lead to changes in the welfare performance of regimes. But, for the model calibration considered here, the extra price flexibility generated by a peg does not compensate for the loss of monetary independence. Inflation targeting yields the highest welfare level despite generating the least price flexibility of the three regimes considered.

Ozge Senay

Department of Economics Middle East Technical University

Ankara 06531

Turkey

osenay@metu.edu.tr
Alan Sutherland
Department of Economics
University of St. Andrews
St Andrews, Fife KY16 9AL
UK
ajs10@st-and.ac.uk 


\section{Introduction}

Recently an extensive literature has developed which analyses the welfare performance of exchange rate regimes in general equilibrium models with sticky-prices (see Devereux and Engel (1998, 2003), Devereux (2000, 2004) and Bachetta and van Wincoop (2000)). This new literature is largely based on models where the degree of price flexibility is exogenously determined and does not change in response to changes in the monetary regime. The welfare comparisons presented in this literature are therefore potentially subject to a form of the Lucas (1976) critique. The Lucas critique suggests that it is implausible that the degree of price flexibility remains unaffected if a change in monetary regime produces a large change in the volatility of output or other important macro variables. There are therefore strong theoretical reasons to investigate the endogenous determination of price flexibility.

In addition to this theoretical motivation for considering endogenous price flexibility, there is a further motivation arising from the policy debate on the choice of monetary regime. It has been argued, for instance, that monetary union in Europe will encourage greater price flexibility which will partly (or completely) offset the loss of monetary independence. This argument can not be addressed within the theoretical structure adopted in most of the current literature.

The proposition that the degree of price flexibility changes endogenously with changes in the monetary policy regime has received some empirical support. Alogoskoufis and Smith (1991), for instance, present estimates of Phillips-curve equations which strongly suggest that changes of the exchange rate regime have resulted in large changes in the degree of inflation inertia. They show that inflation rates in the United States and the United Kingdom became significantly more sluggish in response to shocks after the collapse of the Gold Standard and also after the collapse of the Bretton Woods system. This evidence indicates that the endogeneity of price flexibility may be an important empirical phenomenon.

This paper uses a sticky-price general equilibrium model of a small open economy to analyse the welfare implications of fixed and floating exchange rates. The model departs from much of the recent literature by allowing the degree of price flexibility to be determined endogenously. The home country is subject to stochastic shocks from internal and external sources and the focus of interest is on the stabilisation and welfare implications of regime choice for the home country. Price setting is subject to Calvo-style price contracts but, unlike the standard Calvo (1983) structure, agents are allowed to choose the average frequency of price changes. Agents must balance the benefits of price flexibility against the costs involved in changing prices. Since the benefits of price flexibility depend in large part on the volatility of the macroeconomic environment, the optimally chosen degree of price flexibility differs between exchange rate regimes. The model is used to analyse the stabilising properties of each regime and to carry out a welfare comparison between fixed and floating exchange rates.

The existing literature on exchange rate regime choice has shown that the relative welfare effects of policy regimes are subject to many and varied factors. It is not the 
purpose of this paper to recount this literature, nor is it to provide a definitive welfare analysis of exchange-rate regime choice. The purpose of this paper is to develop a simple model of endogenous price flexibility which is a direct development of the standard framework used in the current literature. This model is used to address two questions: First, in general, can endogenising price flexibility lead to a change in the welfare ranking of monetary policy regimes? Second, more specifically, can a fixed exchange rate regime generate sufficient price flexibility to compensate for the loss of monetary independence implied by the fixed rate? The analysis presented below suggests that the answer to the first question is 'yes', it is possible to identify cases where the ranking of monetary regimes is reversed when compared to the case where price flexibility is exogenous. On the other hand, the results suggest that the answer to the second question is mixed. A fixed rate does lead to greater price flexibility, but this tends to reduce the level of welfare yielded by a fixed rate (relative to the exogenous price flexibility case).

There have been a number of papers that have previously analysed the implications of price flexibility in general and endogenous price flexibility in particular. De Long and Summers (1986) investigate whether increased price and wage flexibility stabilises or destabilises macro variables. They show that increased price and wage flexibility may in fact be destabilising when there is a mixture of supply and demand shocks. Calmfors and Johansson (2002), Devereux (2003), Devereux and Siu (2004), Devereux and Yetman (2002), Dotsey, King and Wolman (1999), Kiley (2000) and Romer (1990) all analyse endogenous price flexibility in one form or another. Devereux and Yetman (2002) analyse the implications of endogenous price flexibility for the long run trade-off between inflation and output. Devereux and Siu (2004), Dotsey, King and Wolman (1999) and Kiley (2000) analyse the impact and propagation of monetary shocks in models with endogenous price flexibility. The main focus of these papers is on the implications of endogenous price flexibility for business cycle behaviour. They do not directly address any implications for welfare or the choice of monetary policy regime.

Calmfors and Johansson (2002) analyse the stabilising properties of endogenising wage flexibility for a small open economy joining a monetary union. Given that joining a monetary union is believed to increase macroeconomic variability, a country facing the loss of monetary independence has an incentive to increase the degree of wage indexation. Calmfors and Johansson show, using a simple linear model with an ad hoc quadratic welfare function, that greater variability in prices which accompanies increased wage flexibility, may in fact be welfare decreasing.

Of the papers in the existing literature, the one most closely related with the present paper is Devereux (2003). This is the only paper to analyse the implications of exchange rate policy for the flexibility of prices in an open economy stochastic general equilibrium model. Devereux shows that a fixed rate regime followed by a single country tends to increase the degree of price flexibility within that country. ${ }^{1}$

\footnotetext{
${ }^{1}$ Devereux (2003) emphasizes the role of strategic complementarity in the incentive of price setters to re-adjust prices ex post and shows that strategic complementarity increases the degree
} 
However, a fixed rate regime followed by two countries (a monetary union) is shown to reduce the degree of price flexibility to a level even below that of a floating regime.

Before proceeding, it may be useful to emphasize the features of the current paper that distinguish it from Devereux (2003). Devereux compares fixed and floating exchange rates in a single-period model where agents can choose in advance to set prices before or after exogenous shocks are realised. The model in this paper differs from the Devereux model in three important respects. Firstly, the model presented here is a fully dynamic framework with multi-period contracts. This implies that the model can be more easily calibrated and matched to relevant real world data. Secondly, the model allows the elasticity of substitution between home and foreign goods to differ from unity (whereas Devereux restricts this elasticity to unity). The model in the current paper can therefore be used to analyse the implications of the expenditure switching effect for the endogeneity of price flexibility. Thirdly and most importantly, the analysis below presents an explicit welfare comparison between monetary policy regimes, whereas Devereux focuses on a purely positive analysis. The contribution of the current paper is therefore to provide a richer model and to analyse the implications of endogenous price flexibility for the welfare performance of regimes.

The paper proceeds as follows. Section 2 presents the structure of the model. Section 3 describes the different policy regimes to be compared. Section 4 discusses the solution method and approximation of the model. Section 5 analyses the comparison between exchange rate regimes under exogenous and endogenous price flexibility, and section 6 concludes the paper.

\section{The Model}

The model is a variation of the sticky-price general equilibrium structure which has become standard in the recent open economy macroeconomics literature (following the approach developed by Obstfeld and Rogoff $(1995,1998)) .{ }^{2}$ As already emphasised, it is not the purpose of this paper to provide a definitive welfare analysis of monetary policy regimes. For simplicity, therefore, and in order to provide a clearer focus on the role of endogenous price flexibility, the model omits some features which have been emphasised in the literature. Thus, for instance, it is assumed that prices are set in the currency of the producer rather than in the currency of the consumer. ${ }^{3}$ Additionally, the range of stochastic shocks disturbing the world economy is limited

of price flexibility.

${ }^{2}$ See Lane (2001) for a recent survey of this literature.

${ }^{3}$ Devereux and Engel $(1998,2003)$ have emphasised the importance of the degree of exchange rate pass-through for the welfare effects of different exchange rate regimes. Obstfeld (2002) on the other hand shows that, if imperfect pass-through exists only at the final goods stage, but not at the intermediate goods stage of production, many of the results obtained in a model of producer currency pricing continue to hold. 
to just labour supply shocks and foreign inflation shocks. ${ }^{4}$ Relaxing these simplifying assumptions will clearly have implications for the relative welfare performance of the different policy regimes considered. This, however, is not the central concern of the present paper. The objective of this paper is to determine if, given a reasonably standard model, endogenising the degree of price flexibility significantly affects the predictions of the model for the relative welfare performance of monetary policy regimes.

The model world consists of two countries, which will be referred to as the home country and the foreign country. The world population is indexed on the unit interval with home agents indexed $h \in[0, n)$ and foreign agents indexed $f \in[n, 1]$. In the numerical exercises reported below $n$ is chosen to be small.

The analysis focuses on the choice of monetary policy regime for the home economy. Three possible regimes are considered for the home economy. The specification of these regimes is described below. Throughout the analysis the foreign monetary authority is assumed to be following a policy of strict targeting of producer-price inflation.

Agents consume a basket of goods containing all home and foreign produced goods. Each agent is a monopoly producer of a single differentiated product. Price setting follows the Calvo (1983) structure. In any given period, agent $j$ is allowed to change the price of good $j$ with probability $\left(1-\gamma_{j}\right)$.

The timing of events is as follows. In period 0 the home monetary authority makes its choice of monetary regime. Immediately following this policy decision, all agents in both countries are allowed to make a first choice of price for trade in period 1 (and possibly beyond). Simultaneously, all agents are also allowed the opportunity to make a once-and-for-all choice of Calvo-price-adjustment probability (i.e. $\gamma_{j}$ ). In each subsequent period, beginning with period 1, stochastic shocks are realised, individual agents receive their Calvo-price-adjustment signal (which is determined by their individual choices of $\gamma$, i.e. $\gamma_{j}$ ), those agents which are allowed to adjust their prices do so, and finally trade takes place.

The detailed structure of the home country is described below. The foreign country has an identical structure (except that the foreign economy is assumed to be large relative to the home economy). Where appropriate, foreign real variables and foreign currency prices are indicated with an asterisk.

\footnotetext{
${ }^{4}$ Starting with the analysis of Poole (1970), it has long been recognised that the relative performance of different monetary policy regimes is influenced by the relative strength of stochastic disturbances.
} 


\subsection{Preferences}

All agents in the home economy have utility functions of the same form. The utility of agent $h$ is given by

$$
U_{t}(h)=E_{t}\left[\sum_{s=t}^{\infty} \beta^{s-t}\left(\frac{C_{s}^{1-\rho}(h)}{1-\rho}+\chi \log \frac{M_{s}(h)}{P_{s}}-\frac{K_{s}}{\mu} y_{s}^{\mu}(h)\right)\right]-A\left(\gamma_{h}\right)
$$

where $\chi$ is a positive constant, $C$ is a consumption index defined across all home and foreign goods, $M$ denotes end-of-period nominal money holdings, $P$ is the consumer price index, $y(h)$ is the output of good $h$ and $E$ is the expectations operator. $K$ is a stochastic shock to labour supply preferences which evolves as follows

$$
\log K_{t}=\zeta_{K} \log K_{t-1}+\varepsilon_{K, t}
$$

where $\varepsilon_{K}$ is symmetrically distributed over the interval $[-\epsilon, \epsilon]$ with $E\left[\varepsilon_{K}\right]=0$ and $\operatorname{Var}\left[\varepsilon_{K}\right]=\sigma_{K}^{2}$.

The expected costs of adjusting prices are represented by the function $A\left(\gamma_{h}\right)$. The form of this function is discussed in more detail below.

The consumption index $C$ for home agents is defined as

$$
C=\left[n^{\frac{1}{\theta}} C_{H}^{\frac{\theta-1}{\theta}}+(1-n)^{\frac{1}{\theta}} C_{F}^{\frac{\theta-1}{\theta}}\right]^{\frac{\theta}{\theta-1}}
$$

where $C_{H}$ and $C_{F}$ are indices of home and foreign produced goods defined as follows

$$
C_{H}=\left[\left(\frac{1}{n}\right)^{\frac{1}{\phi}} \int_{0}^{n} c_{H}(i)^{\frac{\phi-1}{\phi}} d i\right]^{\frac{\phi}{\phi-1}}, \quad C_{F}=\left[\left(\frac{1}{1-n}\right)^{\frac{1}{\phi}} \int_{n}^{1} c_{F}(j)^{\frac{\phi-1}{\phi}} d j\right]^{\frac{\phi}{\phi-1}}
$$

where $\phi>1, c_{H}(i)$ is consumption of home good $i$ and $c_{F}(j)$ is consumption of foreign good $j$. The parameter $\theta$ is the elasticity of substitution between home and foreign goods. This is a key parameter which determines the strength of the expenditure switching effect.

\section{$2.2 \quad$ Price Indices}

The aggregate consumer price index for home agents is

$$
P=\left[n P_{H}^{1-\theta}+(1-n) P_{F}^{1-\theta}\right]^{\frac{1}{1-\theta}}
$$

where $P_{H}$ and $P_{F}$ are the price indices for home and foreign goods respectively defined as

$$
P_{H}=\left[\frac{1}{n} \int_{0}^{n} p_{H}(i)^{1-\phi} d i\right]^{\frac{1}{1-\phi}}, \quad P_{F}=\left[\frac{1}{1-n} \int_{n}^{1} p_{F}(j)^{1-\phi} d j\right]^{\frac{1}{1-\phi}}
$$


The law of one price is assumed to hold. This implies $p_{H}(i)=S p_{H}^{*}(i)$ and $p_{F}(j)=S p_{F}^{*}(j)$ for all $i$ and $j$ where an asterisk indicates a price measured in foreign currency and $S$ is the exchange rate (defined as the domestic currency price of foreign currency). Purchasing power parity holds in terms of aggregate consumer price indices, $P=S P^{*}$.

\subsection{Financial Markets}

It is assumed that international financial trade is restricted to a risk free international real bond which is denominated in units of the consumption basket (which is identical in both countries). ${ }^{5}$ The budget constraint of agent $h$ is given by

$$
\begin{aligned}
P_{t} B_{t}(h)+M_{t}(h)= & \left(1+r_{t}\right) \varphi_{t} P_{t} B_{t-1}(h)+M_{t-1}(h)+p_{H, t}(h) y_{t}(h) \\
& -P_{t} C_{t}(h)-T_{t}+R_{t}(h)
\end{aligned}
$$

where $B(h)$ is bond holdings, $M(h)$ is money holdings, $T$ is a lump-sum government transfer, and $P$ is the aggregate consumer price index.

As is standard in much of the literature, individual agents are assumed to have access to a market for state-contingent assets which allows them to insure against the idiosyncratic income shocks implied by the Calvo pricing structure. ${ }^{6}$ The payoff to agent $h$ 's portfolio of state-contingent assets is given by $R(h)$.

In order to remove the unit root which arises when international financial trade is restricted to non-contingent bonds, bond holdings are subject to a cost which is related to the aggregate stock of bonds held. The holding cost is represented by the multiplicative term $\varphi_{t}$ in the budget constraint, where

$$
\varphi_{t}=1 /\left(1+\delta B_{t-1}\right)
$$

and $B$ is the aggregate holding of bonds by the home population.

Home agents can also hold wealth in the form of a home nominal bond which is not internationally traded but which can be a substitute for the international bond amongst home agents. Likewise, foreign agents may hold a foreign nominal

\footnotetext{
${ }^{5}$ In much of the recent open economy literature it has become standard to assume that international financial markets allow complete consumption risking. In many applications this approach proves to be very simple because it eliminates the need to consider asset stock dynamics. However, the modelling of a complete markets structure becomes much more problematic in an asymmetric world (such as a small open economy of the type under consideration here). Any asymmetry, either in economic structure or in policy, implies an asymmetry in the prices of state-contingent assets. Thus, a correct analysis of a complete markets structure requires explicit modelling of state-contingent assets and the determination of their prices. This complication can be avoided, and thus the model can be considerably simplified, by assuming that international financial trade is restricted to non-contingent bonds. Of course, the distortion implied by the incompleteness of international financial markets has implications for the welfare effects of monetary policy. This point is further discussed below.

${ }^{6}$ There is a separate market for state-contingent assets in each country and there is no international trade in state-contingent assets.
} 
bond which is also not internationally traded but which can be a substitute for the international bond amongst foreign agents. The rate of return on the home nominal bond will be linked to the rate of return on the international bond by the generalised Fisher relationship as follows

$$
\left(1+i_{t}\right)=\left(1+r_{t}\right) \frac{1}{P_{t}} \frac{E\left[C_{t+1}^{-\rho}\right]}{E\left[\frac{C_{t+1}^{-\rho}}{P_{t+1}}\right]}
$$

An equivalent expression holds for the foreign nominal bond.

The government's budget constraint is

$$
M_{t}-M_{t-1}+T_{t}=0
$$

Changes in the money supply are assumed to enter and leave the economy via changes in lump-sum transfers.

\subsection{Consumption Choices}

The intertemporal dimension of home agents' consumption choices gives rise to the familiar consumption Euler equation

$$
\frac{1}{C_{t}^{\rho}}=\beta\left(1+r_{t}\right) \varphi_{t} E_{t}\left[\frac{1}{C_{t+1}^{\rho}}\right]
$$

A similar condition holds for foreign agents.

Individual home demands for representative home good, $h$, and foreign good, $f$, are given by

$$
c_{H}(h)=C_{H}\left(\frac{p_{H}(h)}{P_{H}}\right)^{-\phi}, c_{F}(f)=C_{F}\left(\frac{p_{F}(f)}{P_{F}}\right)^{-\phi}
$$

where

$$
C_{H}=n C\left(\frac{P_{H}}{P}\right)^{-\theta}, C_{F}=(1-n) C\left(\frac{P_{F}}{P}\right)^{-\theta}
$$

Foreign demands for home and foreign goods have an identical structure to the home demands. Individual foreign demand for representative home good, $h$, and foreign good, $f$, are given by

$$
c_{H}^{*}(h)=C_{H}^{*}\left(\frac{p_{H}^{*}(h)}{P_{H}^{*}}\right)^{-\phi}, c_{F}^{*}(f)=C_{F}^{*}\left(\frac{p_{F}^{*}(f)}{P_{F}^{*}}\right)^{-\phi}
$$

where

$$
C_{H}^{*}=n C^{*}\left(\frac{P_{H}^{*}}{P^{*}}\right)^{-\theta}, C_{F}^{*}=(1-n) C^{*}\left(\frac{P_{F}^{*}}{P^{*}}\right)^{-\theta}
$$

The total demand for home goods is $Y=n C_{H}+(1-n) C_{H}^{*}$ and the total demand for foreign goods is $Y^{*}=n C_{F}+(1-n) C_{F}^{*}$. 


\subsection{Price Setting}

In equilibrium, all home agents will choose the same value of $\gamma_{j}$, which will be denoted by $\gamma_{H}$. The determination of $\gamma_{H}$ is discussed below. Thus, in any given period, proportion $\left(1-\gamma_{H}\right)$ of home agents are allowed to reset their prices. All agents who set their price at time $t$ choose the same price, denoted $p_{H, t}$ for the home country. The first-order condition for the choice of prices implies the following.

$$
E_{t}\left\{\sum_{s=t}^{\infty}\left(\beta \gamma_{H}\right)^{s-t}\left[(\phi-1) \frac{p_{H, t} y_{t, s}}{C_{s}^{\rho} P_{s}}-\phi K_{s} y_{t, s}^{\mu}\right]\right\}=0
$$

where $y_{t, s}=Y_{s}\left(p_{H, t} / P_{H, s}\right)^{-\phi}$ is the period-s output of a home agent whose price was last set in period $t$. It is possible to rewrite the expression for aggregate home producer prices as follows

$$
P_{H, t}=\left[\sum_{s=0}^{\infty}\left(1-\gamma_{H}\right) \gamma_{H}^{s} p_{H, t-s}^{1-\phi}\right]^{\frac{1}{1-\phi}}
$$

For the purposes of interpreting some of the results reported later, it proves useful to consider the price that an individual agent would choose if prices could be reset every period. For home agent $j$, this price is denoted $p_{H, t}^{o}(j)$ and is given by the expression

$$
p_{H, t}^{o}(j)=\frac{\phi}{(\phi-1)} K_{s} C_{s}^{\rho} P_{s} y_{t, s}^{\mu-1}(j)
$$

\subsection{Equilibrium Price Flexibility}

Price flexibility is made endogenous in this model by allowing all agents to make a once-and-for-all choice of the Calvo-price-adjustment probability in period zero. ${ }^{7}$ When making decisions with regard to price flexibility each agent acts as a Nash player. Given that all agents are infinitesimally small, the choice of individual $\gamma$ is made while assuming that the aggregate choice of $\gamma$ is fixed. The equilibrium $\gamma$ is assumed to be the Nash equilibrium value (i.e. where the individual choice of $\gamma$ coincides with the aggregate $\gamma$ ).

Agents make their choice of $\gamma$ in order to maximise the discounted present value of expected utility. For simplicity, it is assumed that the utility of real balances is ignored for the purposes of determining the equilibrium value of $\gamma$.

\footnotetext{
${ }^{7}$ An alternative approach would be to assume that agents can choose a value for $\gamma$ every time they reset their prices. A structure of this form would, however, be extremely difficult to solve because it would be necessary to track the distribution of $\gamma^{\prime}$ s across the population of agents as the economy evolves. The solution of the model is made much more manageable by restricting the choice of $\gamma$ to an initial once-and-for-all decision. Given that the main objective is to investigate how the choice of $\gamma$ responds to the choice of monetary regime, and given that the choice of regime is itself a once-and-for-all decision, it seems unlikely that much is lost by restricting the choice of $\gamma$ in this way.
} 
From the point of view of the individual agent, the optimal $\gamma$ is the one which equates the marginal benefits of price flexibility with the marginal cost of price adjustment. The benefits of price flexibility arise because a low value of $\gamma$ implies that the individual price can more closely respond to shocks. The costs of price adjustment may take the form of menu costs, information costs, decision making costs and other similar costs. These costs of price adjustment are captured by the function $A(\gamma)$ in equation (1). It is assumed that the cost of price adjustment is proportional to the expected number of price changes per period. Thus $A(\gamma)$ is of the following form

$$
A(\gamma)=\frac{\alpha}{1-\beta}(1-\gamma)
$$

where $\alpha>0$ and the factor $1 /(1-\beta)$ converts the per-period cost of price changes to the present discounted value at time zero. It is important to note that the cost of price flexibility is a function of the average rate of price adjustment, and is not linked to actual price changes.

As described above, individual agents are assumed to have access to insurance markets which allow them to insure against the idiosyncratic income shocks implied by the Calvo pricing structure. It is important to specify that, in the case of the present model, these markets open after all agents have made their choices of price adjustment probability.

\section{Monetary Policy}

The main focus of attention in this paper is on the choice of monetary regime for the small home economy. The objective is to compare a fixed exchange rate regime with a floating exchange rate regime. The specification of a fixed exchange rate is simple. In this case, the home monetary authority is assumed to vary the home nominal interest rate in order to maintain the exchange rate at a target rate, denoted $\bar{S}$. The fixed rate is therefore a unilateral (or one-sided) peg in the sense that it is the actions of the home monetary authority which sustain the regime.

While a fixed-rate regime is uniquely defined, there are many different forms of floating-rate regime which could be adopted by the home economy. Two alternatives are considered: money targeting and strict targeting of the rate of inflation of producer prices. Money targeting is a natural case to consider because it corresponds to the traditional 'textbook' definition of a floating exchange rate. Inflation targeting is also a natural case to consider because it corresponds to the policy actually adopted by many countries in recent years. ${ }^{8}$

\footnotetext{
${ }^{8}$ In principle, it would be possible to consider other simple monetary regimes for the home economy. Alternatives include, for instance, a Taylor rule or nominal income targeting. However, in order to allow attention to be focused on the role of endogenous price flexibility, the current analysis is confined to a comparison of money targeting, inflation targeting and a fixed nominal exchange rate.
} 
In the case of money targeting the home monetary authority fixes the level of the home money supply at a level $\bar{M}$ and allows the nominal interest rate to be determined by equilibrium in the market for real money balances. The demand for money is defined by the first-order condition for the choice of money holdings, which is given by the following

$$
\chi\left(\frac{M_{t}}{P_{t}}\right)^{-1}=\left(\frac{i_{t}}{1+i_{t}}\right) C_{t}^{-\rho}
$$

In the case of strict targeting of producer-price inflation, the home monetary authority varies the home nominal interest rate to ensure that the rate of inflation of producer prices achieves a target rate of zero, thus

$$
\frac{P_{H, t}}{P_{H, t-1}}=1
$$

In what follows, this regime will be referred to as 'inflation targeting'. It should be borne in mind, however, that this refers to targeting of producer-price inflation not consumer-price inflation.

It is important to emphasise that, even in the case where the degree of price flexibility is exogenously determined, none of the three policy regimes just described is fully optimal for the home economy. In particular, it should be noted that, unlike in the model of Clarida, Gali and Gertler (2001), a policy of inflation stabilisation is not fully optimal for the home economy in this model. There are two reasons for this: a non-unit elasticity of substitution between home and foreign goods; and the incompleteness of international financial markets. Sutherland (2004) shows that, in general, producer-price stabilisation is not optimal (for a small open economy) when the elasticity of substitution between home and foreign goods differs from unity, ${ }^{9}$ and Devereux (2004) and Benigno (2001) show that price or inflation stabilisation is not optimal when international financial markets are incomplete. Given these factors, there is no reason to suppose, a priori, that inflation targeting will dominate the other two regimes.

In principle, it would be possible to derive fully optimal monetary policy rules for the home economy. However, the complications caused by endogenous price flexibility make this infeasible given currently available solution techniques. Attention is therefore confined to a comparison of the three simple, but non-optimal, policy regimes specified above.

Finally, it is necessary to specify the behaviour of the foreign monetary authority. The foreign monetary authority is assumed to adopt a rule for the foreign nominal

\footnotetext{
${ }^{9}$ It is important to note that, even when price stability is optimal from the point of view of a global cooperative policymaker, it is not necessarily optimal for an individual country acting to maximise national welfare. Benigno and Benigno (2003) study the conditions under which price stability is optimal for cooperative and non-cooperative policymaking in a two-country model where the elasticity of substitution between home and foreign goods can differ from unity.
} 
interest rate which ensures that the rate of inflation of producer prices achieves a target rate $\pi_{t}^{*}$, thus

$$
\frac{P_{F, t}^{*}}{P_{F, t-1}^{*}}=\pi_{t}^{*}
$$

As with many other aspects of the model, the policy rule adopted by the foreign monetary authority can affect the welfare comparison between monetary regimes for the home economy. An inflation targeting policy is a natural benchmark for the foreign economy because such a policy is, in fact, optimal from the point of view of foreign welfare. ${ }^{10}$ It is also a reasonable approximation to the monetary policy operated by large economies such as the United States and those of the Eurozone countries.

The inflation target in the foreign country is assumed to be subject to stochastic shocks such that $\pi_{t}^{*}$ evolves as follows

$$
\log \pi_{t}^{*}=\zeta_{\pi^{*}} \log \pi_{t-1}^{*}+\varepsilon_{\pi^{*}, t}
$$

where $\varepsilon_{\pi^{*}}$ is symmetrically distributed over the interval $[-\epsilon, \epsilon]$ with $E\left[\varepsilon_{\pi^{*}}\right]=0$ and $\operatorname{Var}\left[\varepsilon_{\pi^{*}}\right]=\sigma_{\pi^{*}}^{2}$. The stochastic shocks to the foreign inflation target represent exogenous changes in policy which may arise from changes in political pressure on the foreign monetary authority or changes in the composition of its governing council or policymaking committee. Alternatively the shocks may represent policy mistakes made by the foreign monetary authority. In either case, the shocks are exogenous from the point of view of the home country. In the context of the current model, these shocks represent a form of foreign monetary shock.

\section{Model Solution}

It is not possible to derive an exact solution to the model described above. The model is therefore approximated around a non-stochastic equilibrium (defined as the solution which results when $K=K^{*}=\pi^{*}=1$ and $\sigma_{K}^{2}=\sigma_{K^{*}}^{2}=\sigma_{\pi^{*}}^{2}=0$ ). For any variable $X$ define $\hat{X}=\log (X / \bar{X})$ where $\bar{X}$ is the value of variable $X$ in the non-stochastic equilibrium. $\hat{X}$ is therefore the log-deviation of $X$ from its value in the non-stochastic equilibrium.

Aggregate (per capita) home welfare in period 0 is defined as

$$
\Omega=\frac{1}{n} E_{0} \sum_{s=0}^{\infty} \beta^{s}\left\{\int_{0}^{n}\left(\frac{C_{s}^{1-\rho}(h)}{1-\rho}-\frac{K_{s}}{\mu} y_{s}^{\mu}(h)\right) d h\right\}-\frac{\alpha}{1-\beta}(1-\gamma)
$$

where, for simplicity, the utility of real balances is excluded.

\footnotetext{
${ }^{10}$ In all the results presented below, the foreign economy is assumed to be so large that, in effect, it is a closed economy. The factors which undermine the optimality of inflation targeting for the home economy (i.e. incomplete international financial markets and the non-unit elasticity of substitution between home and foreign goods) therefore do not apply to the foreign economy.
} 
A second-order approximation of $\Omega$ can be written as follows

$$
\begin{gathered}
\Omega-\bar{\Omega}=\bar{C}^{1-\rho} E_{0} \sum_{s=0}^{\infty} \beta^{\tau}\left\{\hat{C}_{s}+\frac{1}{2}(1-\rho) \hat{C}_{s}^{2}\right. \\
\left.-\frac{\phi-1}{\phi}\left[\hat{Y}_{s}+\frac{1}{2} \mu\left(\hat{Y}_{s}+\frac{1}{\mu} \hat{K}_{s}\right)^{2}+\frac{1}{2} \phi(1+\phi(\mu-1)) \Pi_{s}\right]\right\} \\
-\frac{\alpha}{1-\beta}(\bar{\gamma}-\gamma)+O\left(\epsilon^{3}\right)
\end{gathered}
$$

where

$$
\Pi_{s}=\sum_{i=0}^{\infty}(1-\gamma) \gamma^{i}\left(\hat{p}_{H, s-i}-\hat{P}_{H, s}\right)^{2}
$$

where $O\left(\epsilon^{3}\right)$ contains terms of order higher than two in the variables of the model. ${ }^{11}$

In order to derive a solution to the endogenous price flexibility problem it is also necessary to consider the utility of a representative individual agent. A second-order approximation of period-0 utility of agent $h$ is

$$
\begin{array}{r}
U_{0}(h)-\bar{U}=\bar{C}^{1-\rho} E_{0} \sum_{s=0}^{\infty} \beta^{s}\left\{\hat{C}_{s}(h)+\frac{1}{2}(1-\rho) \hat{C}_{s}^{2}(h)\right. \\
\left.-\frac{\phi-1}{\phi}\left[\hat{y}_{s}(h)+\frac{1}{2} \mu\left(\hat{y}_{s}(h)+\frac{1}{\mu} \hat{K}_{s}\right)^{2}\right]\right\} \\
-\frac{\alpha}{1-\beta}\left(\bar{\gamma}-\gamma_{h}\right)+O\left(\epsilon^{3}\right)
\end{array}
$$

Note that the second-order approximations of both aggregate and individual utilities depend on the first and second moments of consumption and output. Aggregate utility also depends on the second moments of prices. In order to analyse aggregate and individual utility it is necessary to derive second-order accurate solutions for the first moments of the variables of the model. These solutions are obtained numerically using the technique described in Sutherland (2002).

A numerical search technique is used to locate Nash equilibria in the choice of $\gamma$. The procedure is as follows. An initial guess for the equilibrium $\gamma$ is selected. The model is then solved for this value of $\gamma$ and the discounted value of utility for an individual agent is calculated (using the expression for individual utility given in (27)). The model is then re-solved with a perturbed value of $\gamma_{h}$ for a single individual, but with the value of $\gamma$ for all other agents fixed. The discounted value of utility for individual $h$ is then re-evaluated at this perturbed value of $\gamma_{h}$. This provides a measure of the incentive for individual $h$ to deviate from the aggregate $\gamma$. If this incentive is non-zero, the procedure is repeated with a new choice of aggregate

\footnotetext{
${ }^{11}$ All log-deviations from the non-stochastic equilibrium are of the same order as the shocks, which (by assumption) are of maximum size $\epsilon$. When presenting an equation which is approximated up to order two it is therefore possible to gather all terms of order higher than two in a single term denoted $O\left(\epsilon^{3}\right)$.
} 
$\gamma$. The procedure is repeated until a value of $\gamma$ is found where the incentive to deviate is zero - in which case a Nash equilibrium has been identified.

In all the examples considered below, the foreign country is large relative to the home country, so the foreign equilibrium value of $\gamma$ does not depend on the home value of $\gamma$. The foreign $\gamma$ is also invariant to the choice of monetary regime in the home country and to the value of $\theta$ (the elasticity of substitution between home and foreign goods). On the other hand, the equilibrium value of $\gamma$ for the home economy depends on the choice of regime and the value of $\theta$. The search procedure for the home economy must therefore be repeated for each policy regime and each value of $\theta$.

The next section reports numerical solutions to the above model which allow a comparison to be made between the three monetary regimes. The numerical solutions are obtained using the set of parameter values in Table 1 . The values for $\rho, \phi, \mu$ and $\beta$ are taken from Rotemberg and Woodford (1999). The value for $\delta$ (i.e. the parameter determining the costs of bond holdings) is based on the calibration used by Benigno (2001).

We consider a range of values of $\theta$ (i.e. the elasticity of substitution between home and foreign goods) between 1 and $10 .{ }^{12}$ The empirical literature on the elasticity of substitution between home and foreign goods does not provide any clear guidance on an appropriate value for this parameter. Obstfeld and Rogoff (2000) briefly survey some of the relevant literature and quote estimates for the elasticity ranging between 1.2 and 21.4 for individual goods (see Trefler and Lai (1999)). Estimates for the average elasticity across all traded goods lie in the range 5 to 6 (see for instance Hummels (2001)). Anderson and van Wincoop (2003) also survey the empirical literature on trade elasticities and conclude that a value between 5 and 10 is reasonable. On the other hand, the real business cycle literature typically uses a much smaller value for this parameter. For instance Chari, Kehoe and McGrattan (2002) use a value of 1.5 in their analysis.

In addition to the lack of firm empirical guidance on values for $\theta$, there are good theoretical reasons to consider a range of values for this parameter. In a previous paper (Senay and Sutherland (2004)), using a model where the degree of price flexibility is exogenously determined, it was shown that the expenditure switching effect can play a significant role in the welfare comparison between regimes. It was found that the key mechanism which drives the relative welfare performances of fixed and floating regimes is the impact of regime choice on the volatility of output. The volatility of output is particularly sensitive to the choice of exchange rate regime when the expenditure switching effect is strong. Given that the volatility of output is likely to have a significant impact on the incentive of agents to choose

\footnotetext{
${ }^{12}$ In principle $\theta$ can be less than unity. Sutherland (2004), using a model with an exogenously fixed degree of price flexibility, analyses the case where $\theta$ is less than unity and shows that many of the welfare effects of monetary policy are reversed in this region. The theoretical complications that arise when $\theta$ is less than unity are not directly relevant to the subject of the current paper, so attention is confined to values of $\theta$ greater than unity. In addition, the bulk of the empirical evidence suggests that this is the relevant range.
} 
a high degree of price flexibility, there may be an important interaction between the expenditure switching effect, the degree of price flexibility and the choice of exchange rate regime. The results reported below show that this interaction is indeed potentially important.

Of all the parameters of the model, the most difficult to calibrate is $\alpha$, i.e. the coefficient in the function determining the costs of price adjustment (equation 19). The function $A(\gamma)$ in principle captures a wide range of costs associated with price adjustment. Not all these costs are directly measurable, so there is no simple empirical basis on which to select a value for $\alpha$. As a starting point, for the purposes of illustration, the value of $\alpha$ is set at 0.003 in the benchmark case. This implies aggregate price adjustment costs of 0.075 per cent of GDP if prices are adjusted at an average rate of once every four quarters (which is consistent with $\gamma=0.75$ ). This total aggregate cost is not implausibly high, given the potentially wide range of costs incorporated in $A(\gamma)$, but it is acknowledged that a more satisfactory basis needs to be found for calibrating $\alpha$. In order to test the sensitivity of the main results, the implications of setting $\alpha$ to 0.004 are also briefly considered.

The numerical solutions to the model are presented in Figures 1 to 7 . Figure 1 shows the equilibrium value of $\gamma$ for each regime for a range of values of $\theta$. In order to understand the results, it is useful to compare the effects of endogenous price flexibility with a version of the model where the degree of price flexibility is fixed exogenously. Figures 2 to 7 therefore show this comparison. In each figure the left-hand panel shows results for exogenous price flexibility (where $\gamma$ is fixed at 0.75 ) for a range of values of $\theta$ and the right-hand panel shows results for endogenous price flexibility for the same range of values for $\theta$. Figure 2 shows results for welfare. Figures 3 to 7 show the volatilities of a number of relevant variables.

$\begin{array}{ll}\text { Discount factor } & \beta=0.99 \\ \text { Elasticity of substitution for individual goods } & \phi=7.66 \\ \text { Work effort preference parameter } & \mu=1.47 \\ \text { Elasticity of intertemporal substitution } & \rho=1 \\ \text { Bond holding costs } & \delta=0.0005 \\ \text { Price adjustment costs } & \alpha=0.003 \\ \text { Labour supply shocks } & \zeta_{K}=\zeta_{K^{*}}=0.9, \sigma_{K}=\sigma_{K^{*}}=0.01 \\ \text { Foreign inflation shocks } & \zeta_{\pi^{*}}=0.9, \sigma_{\pi^{*}}=0.001 \\ \text { Home country size } & n=0.001\end{array}$

Table 1: Parameter Values 


\section{Comparison of Exchange Rate Regimes}

\subsection{Exogenous Price Flexibility}

The comparison between the three monetary regimes is first considered in the case where price flexibility is exogenously determined (with $\gamma=0.75$ ). Figure 2(a) shows the welfare comparison between regimes. In this figure (and all other figures showing welfare comparisons), welfare is measured in terms of the equivalent compensating percentage variation in steady state consumption. There are two features of Figure 2(a) which are worth noting.

First, inflation targeting yields the highest welfare for values of $\theta$ greater than unity. As already emphasised, a number of features of the model imply that fully optimal monetary policy will generate some volatility in the producer price index. Inflation stabilisation is therefore not fully optimal and there is no a priori reason to suppose that inflation targeting should be the best of the three regimes considered here. Nevertheless it is clear that, for the calibration illustrated and for values of $\theta$ greater than unity, inflation targeting is closer to the fully optimal policy than either of the other policy regimes considered. Thus, the presence of incomplete financial markets and a relatively powerful expenditure switching effect are not sufficient to make either of the other two regimes better than inflation targeting (for the parameter range considered).

The second feature of the welfare comparison in Figure 2(a) which should be noted is that a fixed exchange rate yields relatively low welfare for low values of $\theta$, but it can yield higher welfare than money targeting for higher values of $\theta$. The welfare performance of money targeting declines quite sharply for high values of $\theta$. This is because money targeting causes high volatility of output for high values of $\theta$ - as can be seen in Figure 3(a). This, in turn, is caused by relatively high volatility in the terms of trade for high values of $\theta$ - as shown in Figure 6(a). High volatility of output has a negative effect on welfare (as can be seen from the approximated welfare measure given in equation (25)). These effects are similar to those identified in Senay and Sutherland (2004).

\subsection{Endogenous Price Flexibility}

Now consider the implications of endogenising the degree of price flexibility. Recall that the degree of price flexibility is determined by the parameter $\gamma$. Low values of $\gamma$ imply very flexible prices, while values of $\gamma$ close to unity imply very rigid prices. The equilibrium degree of price flexibility depends on the interaction between many different factors. At the micro level, $\gamma$ is determined by the balance between the benefits and costs of price adjustment. At this level, from the point of view of the individual agent, the benefits of price flexibility will be affected by factors such as the volatility of output, consumption and prices, as well as the covariances between these variables. In turn, at the macro level, the volatilities of these variables will be affected by the aggregate degree of price flexibility itself. Thus, the value of $\gamma$ will be 
determined as part of the general equilibrium interaction of all these different factors. Furthermore, the equilibrium will be affected by strategic interaction between agents in their individual choices of $\gamma^{\prime}$ s. It is likely that there is a strong degree of strategic complementarity between agents in their choice of $\gamma$ - i.e. an individual agent's choice of $\gamma$ will be positively related to the aggregate choice of $\gamma$.

Figure 1 plots the equilibrium values of $\gamma$ for the home country for a range of values of $\theta$. There are three features of this figure which should be noted. First, the equilibrium value of $\gamma$ in the inflation targeting regime is unity. Second, money targeting leads to a negative relationship between $\gamma$ and $\theta$, with relatively low values of equilibrium $\gamma$ for high values of $\theta$. And third, the fixed exchange rate leads to a positive relationship between $\gamma$ and $\theta$, with relatively low values of equilibrium $\gamma$ for low values of $\theta$. (Notice also that, for some ranges of $\theta$, money targeting gives rise to corner solutions, where the equilibrium value of $\gamma$ is unity.)

Despite the potentially complex interactions which determine the equilibrium $\gamma$, it is possible to gain some insight into the mechanisms at work by considering the volatilities of some of the main macro variables shown in Figures 3 to 7 . In particular, consider the optimal price $\left(p_{H, t}^{o}\right)$, or, more specifically, consider the gap between the optimal price and the actual price level. This 'price gap' is the difference between the price that agents would like to set if it was possible to reset prices every period and the average price actually set. The volatility of the 'price gap' is plotted in Figure 5(a). When this price gap is very volatile in the exogenous-price-flexibility case it indicates a strong (latent) incentive to vary prices. Conversely, when the price gap is very stable there is little incentive to vary prices. Thus, for the inflation targeting regime, Figure 5(a) shows that the price gap is completely stable. There is thus no pressure for agents to choose a high degree of price flexibility in this regime. This explains why the equilibrium $\gamma$ in the inflation targeting case is unity (as shown in Figure 1). The equilibrium $\gamma$ 's in the other monetary regimes are also inversely related to the volatility of the price gap. Money targeting causes high volatility of the price gap at high values of $\theta$ and this translates into a low equilibrium value of $\gamma$ (as shown in Figure 1), while the fixed rate regime causes a high volatility of the price gap at low values of $\theta$ and this likewise leads to a low equilibrium value of $\gamma$.

The behaviour of the price gap can, in turn, be traced to the behaviour of other variables. In the case of money targeting, the most important variable appears to be output. As previously explained, with exogenous price flexibility, at high values of $\theta$, output is very volatile in the money targeting regime (see Figure 3(a)). Equation (18) shows that output is one of the main determinants of the optimal price, hence high output volatility leads to high volatility of the optimal price and high volatility of the price gap. This creates a strong incentive to choose a low value of $\gamma$. Notice from Figure 3(b) that, in the endogenous-price-flexibility case, the extra price flexibility induced by the money targeting regime at high values of $\theta$ leads to more stable output compared to the exogenous-price-flexibility case.

It is important to note that, while money targeting creates excessive output volatility at high values of $\theta$, agents do not desire completely to stabilise output. A 
positive $K$ shock implies that home agents would prefer to work less. Thus agents would like output to be negatively correlated with $K$. The foreign labour supply shocks and inflation shocks (by causing fluctuations in the demand for home goods) also create changes in the desired output levels of home agents. For these reasons, a more accurate impression of the degree of excess volatility of output can be obtained by considering the 'output gap', i.e. the difference between actual output and the level of output in a flexible price equilibrium. The volatility of the output gap is shown in Figure 4. Figure 4(a) shows that in the exogenous-price-flexibility case, as with the absolute output level, money targeting creates high volatility of the output gap for high values of $\theta$. Figure 4(b) shows that the extra price flexibility induced by the money targeting regime at high levels of $\theta$ leads to a more stable output gap.

Notice from Figure 4(a) that the inflation targeting regime perfectly replicates the flexible price equilibrium and thus perfectly stabilises the output gap.

The explanation for the relatively low equilibrium value of $\gamma$ in the fixed rate regime, shown in Figure 1, is also related to the behaviour of the output gap. The important mechanism here is the impact of the fixed nominal exchange rate on movements in the terms of trade. A fixed nominal exchange rate combined with sticky nominal prices tends to suppress movements in the terms of trade (as can be seen in Figure 6(a)). This, in turn, tends to prevent output from responding appropriately to the labour supply shocks. There is thus an incentive to adjust prices in order to generate the required movement in the terms of trade. This translates into a low equilibrium value of $\gamma$ in the endogenous-price-flexibility case. This effect is strongest at low values of $\theta$ because the terms of trade movements necessary to produce the required movement in output are larger when $\theta$ is small (because the expenditure switching is relatively weak in this case).

The results just described for the fixed rate regime are consistent with the policy argument described in the introduction to the paper, namely that a fixed rate regime, such as the European monetary union, may lead to greater price flexibility, which, in turn, may offset the negative welfare effect of the loss of monetary policy independence.

Having constructed a model which generates an increase in price flexibility in a fixed rate regime, the crucial question which must now be considered is whether the increase in price flexibility leads to an improvement in the welfare performance of the fixed rate regime. This question can be addressed by considering Figure 2(b). This figure shows the welfare comparison between regimes in the endogenousprice-flexibility case. It is immediately apparent from this figure that endogenous price flexibility makes little difference to the first-ranked policy regime, i.e. inflation targeting continues to yield the highest level of welfare of the three regimes for values of $\theta$ greater than unity.

Despite the continued welfare superiority of inflation targeting, endogenous price flexibility does lead to a number of changes to the welfare performance of the other two regimes which are worth highlighting. Firstly, the extra price flexibility induced by money targeting at high levels of $\theta$ leads to a reduction in the level of welfare 
when compared to the exogenous-price-flexibility case (see Figures 2(a) and 2(b)). The greater price flexibility induced by money targeting does lead to lower output volatility for high levels of $\theta$ (as can be seen from a comparison between Figures 3(a) and $3(\mathrm{~b}))$. This reduction in output volatility does have a positive welfare effect. But this is more than offset by the greater costs of price adjustment which are incurred when the equilibrium value of $\gamma$ is low. The negative welfare effect of price flexibility is sufficiently strong to imply that the welfare ranking of money targeting relative to the fixed exchange rate regime is reversed for values of $\theta$ (approximately) in the range $7<\theta<9$.

Figure 2(b) also shows that the extra price flexibility generated by the fixed exchange rate at low values of $\theta$ reduces the welfare yielded by the fixed rate. The extra price flexibility induced by the fixed rate does lead to more variability in the terms of trade (as can be seen from a comparison of Figures 6(a) and 6(b)). This has a positive welfare effect because the terms of trade can now respond more easily to labour supply shocks. But this welfare benefit is more than offset by the extra costs of price flexibility arising from the low value of $\gamma$. The net result is that the fixed exchange rate is significantly worse than both money targeting and inflation targeting at low values of $\theta$.

Thus, for both the fixed rate regime (at low values of $\theta$ ) and the money targeting regime (at high values of $\theta$ ) extra price flexibility appears to have a negative impact on welfare. At first sight this may appear surprising. After all, given that agents are individually choosing the degree of price flexibility in order to maximise individual utility, why do agents end up choosing a level of price flexibility which yields lower aggregate utility? The explanation is that, in their individual choices of price flexibility, agents are acting non-cooperatively. Furthermore, there is a strong degree of strategic complementarity in the choice of price flexibility which implies that the Nash equilibrium value of $\gamma$ is likely to be very different from the socially optimal $\gamma$. In the cases considered here, it appears that the Nash equilibrium in the choice of $\gamma$ results in excessively low values of $\gamma$. Thus the welfare benefits of greater price flexibility are outweighed by the high costs of price flexibility.

The results in Figures 2(a) and 2(b) can now be used to address the two questions outlined in the introduction to this paper. The first question related to the impact of endogenous price flexibility on the welfare ranking of regimes. Figures 2(a) and 2(b) show that, while the first ranked regime is unchanged, there is a change in the welfare ranking of the fixed rate and money targeting regimes for values of $\theta$ in the range $7<\theta<9$. The second question related to the proposition that a fixed exchange rate may create sufficient price flexibility to offset the loss of monetary independence. The results in Figure 1, 2(a) and 2(b) show that, while a fixed rate does lead to greater price flexibility at low values of $\theta$, this has an overall negative impact on welfare. Greater price flexibility therefore does not compensate for the loss of monetary independence.

Before concluding, it is necessary briefly to consider the extent to which the results just described are sensitive to variations in the parameters of the model. Two 
parameters are likely to be particularly important. One is $\alpha$, which determines the costs of price flexibility (in equation 19). The other is $\phi$, the elasticity of substitution between individual goods. The role of $\alpha$ is obvious: the more costly it is to have flexible prices, the less the degree of price flexibility will change in response to a change in monetary regime. The role of $\phi$ is more subtle. The parameter $\phi$ determines the price elasticity of demand for individual goods, (see equations (12) and (14)). Thus, when $\phi$ is large, any increase in the degree of aggregate price flexibility, which is accompanied by an increase in aggregate price volatility, will generate a strong effect on the volatility of output for an individual agent. The presence of high aggregate price flexibility therefore creates a strong incentive for the individual agent also to choose a high degree of price flexibility. Thus, a high value of $\phi$ implies a high degree of strategic complementarity between agents in their choice of price flexibility.

Figures 8 and 9 show the implications of a higher value of $\alpha$. For these figures $\alpha$ is set at 0.004 (which implies aggregate price adjustment costs of 0.1 per cent of GDP if prices are adjusted at an average rate of once every four quarters). Figure 8 shows the resulting equilibrium values of $\gamma$ for the three monetary regimes. It is clear that the same general pattern of results emerges, except that the values of the equilibrium $\gamma$ 's are higher than in the benchmark case. Figure 9 shows the welfare comparison (where again the left panel shows the case of exogenous price flexibility and the right panel shows the case of endogenous price flexibility). The qualitative pattern of the welfare comparison is very similar to the benchmark case.

Figures 10 and 11 show the implications of a lower value of $\phi$. For these figures $\phi$ is set at 4.0. As explained above, this reduces the degree of strategic complementarity between agents in their choices of $\gamma$. This implies that the equilibrium value of $\gamma$ should be less sensitive to a change in monetary regime. This is confirmed in Figure 10. The qualitative pattern of the welfare comparison (shown in Figure 11) is again broadly similar to the benchmark case.

\section{Concluding Comments}

This paper has analysed the implications of endogenous price flexibility in a general equilibrium model where agents may choose the frequency of price changes. The welfare effects of three policy regimes are compared under both exogenous and endogenous determination of price flexibility. The introduction to the paper outlined two reasons for considering these issues. One was related to the Lucas critique, i.e. does a change in policy regime lead to an endogenous change in price flexibility which alters the welfare performance of regimes? The second was a more policy related question, namely, does a fixed exchange rate generate sufficient price flexibility to offset the welfare cost of the loss of monetary independence? The results described above appear to confirm that endogenous price flexibility can lead to a significant change in the welfare performance of regimes. In one case these changes can change the welfare ranking of regimes. On the other hand, while a fixed exchange rate does 
generate more flexible prices, this extra price flexibility does not compensate for the loss of monetary independence. In fact, when a monetary regime generates more price flexibility, the overall impact on welfare appears to be negative.

Clearly, the results presented above are potentially highly dependent on the form of the model and the specific parameterisation used. A much more extensive sensitivity analysis is required before firmer conclusions can be drawn. The analysis has shown that the equilibrium degree of price flexibility is potentially sensitive to the choice of regime, the costs of price adjustment and strategic complementarity effects (see Figures 1, 8 and 10). A simple linear function is used to model the costs of price flexibility. Given the potentially important role played by the costs of price flexibility, experimentation with other functional forms for this cost function is a priority. The determinants of the degree of strategic complementarity in the choice of price flexibility also require further investigation.

\section{References}

[1] Anderson, James and Eric van Wincoop (2003) "Trade Costs" Boston College and the University of Virginia, unpublished manuscript.

[2] Alogoskoufis, George S. and Ron Smith (1991) "The Phillips Curve, The Persistence of Inflation and the Lucas Critique: Evidence from Exchange-Rate Regime" American Economic Review, 81, 1254-1275.

[3] Bachetta, Philippe and Eric van Wincoop (2000) "Does Exchange Rate Stability Increase Trade and Welfare?" American Economic Review, 90, 1093-1109.

[4] Benigno, Pierpaolo (2001) "Price Stability with Imperfect Financial Integration” CEPR Discussion Paper No. 2854.

[5] Benigno, Gianluca and Pierpaolo Benigno (2003) "Price Stability in Open Economies" Review of Economics Studies, 70, 743-764.

[6] Calmfors, Lars and Asa Johansson (2002) "Nominal Wage Flexibility, Wage Indexation and Monetary Union" IIES Seminar Paper No. 716.

[7] Calvo, Guillermo A. (1983) "Staggered Prices in a Utility-Maximising Framework" Journal of Monetary Economics, 12, 383-398.

[8] Chari, V. V. , Patrick J. Kehoe and Ellen R. McGrattan (2002) "Can Sticky Price Models Generate Volatile and Persistent Real Exchange Rates?" Review of Economic Studies, 69, 533-564.

[9] Clarida, Richard H., Jordi Gali and Mark Gertler (2001) "Optimal Monetary Policy in Open versus Closed Economies: An Integrated Approach" American Economic Review (Papers and Proceedings), 91, 248-252. 
[10] De Long, J. Bradford and Lawrence H. Summers (1986) "Is Increased Price Flexibility Stabilizing?" American Economic Review, 76, 1031-1044.

[11] Devereux, Michael B. (2000) "A Simple Dynamic General Equilibrium Model of the Trade-off between Fixed and Floating Exchange Rates" CEPR Discussion Paper No. 2403.

[12] Devereux, Michael B. (2003) "Exchange Rate Policy and Endogenous Price Flexibility", University of British Columbia, unpublished manuscript.

[13] Devereux, Michael B. (2004) "Should the Exchange Rate be a Shock Absorber?" Journal of International Economics, 62, 359-377.

[14] Devereux, Michael B. and Charles Engel (1998) "Fixed vs. Floating Exchange Rates: How Price Setting Affects the Optimal Choice of Exchange Rate Regime" NBER Working Paper No. 6867.

[15] Devereux, Michael B. and Charles Engel (2003) "Monetary Policy in an Open Economy Revisited: Price Setting and Exchange Rate Flexibility" Review of Economic Studies, 70, 765-783.

[16] Devereux, Michael B. and Henry E. Siu (2004) "State Dependent Pricing and Business Cycle Asymmetries" University of British Columbia, unpublished manuscript.

[17] Devereux, Michael B. and David Yetman (2002) "Menu Costs and the Long Run Output-Inflation Trade-off" Economic Letters, 76, 95-100.

[18] Dotsey, Michael, Robert King and Alexander L. Wolman (1999) "State Dependent Pricing and the General Equilibrium Dynamics of Money and Output" Quarterly Journal of Economics, 114, 655-690.

[19] Hummels, David (2001) "Towards a Geography of Trade Costs" Purdue University, unpublished manuscript.

[20] Kiley, Michael T. (2000) "Endogenous Price Stickiness and Business Cycle Persistence" Journal of Money, Credit and Banking, 32, 28-53.

[21] Lane, Phillip (2001) "The New Open Economy Macroeconomics: A Survey" Journal of International Economics, 54, 235-266.

[22] Lucas, Robert E. (1976) "Econometric Policy Evaluation: A Critique" Carnegie-Rochester Conference Series on Public Policy, 1, 19-46.

[23] Obstfeld, Maurice (2002) "Inflation Targeting, Exchange Rate Pass-through and Volatility" American Economic Review (Papers and Proceedings), 92, 102107. 
[24] Obstfeld, Maurice and Kenneth Rogoff (1995) "Exchange Rate Dynamics Redux" Journal of Political Economy, 103, 624-660.

[25] Obstfeld, Maurice and Kenneth Rogoff (1998) "Risk and Exchange Rates" NBER Working Paper No. 6694.

[26] Obstfeld, Maurice and Kenneth Rogoff (2000) "The Six Major Puzzles in International Macroeconomics: Is There a Common Cause?" NBER Macroeconomics Annual, 15, 339-390.

[27] Poole, William (1970) "Optimal Choice of Monetary Instruments in a Simple Stochastic Macro Model" Quarterly Journal of Economics, 84, 197-216.

[28] Romer, David (1990) "Staggered Price Setting with Endogenous Frequency of Adjustment" Economics Letters, 32, 205-210.

[29] Rotemberg, Julio J. and Michael Woodford (1999) "Interest Rate Rules in an Estimated Sticky Price Model" in John B Taylor (ed) Monetary Policy Rules, University of Chicago Press, Chicago.

[30] Senay, Ozge and Alan Sutherland (2004) "The Expenditure Switching Effect and Fixed versus Floating Exchange Rates" CEPR Discussion Paper No. 4300.

[31] Sutherland, Alan (2002) "A Simple Second-Order Solution Method for Dynamic General Equilibrium Models" CEPR Discussion Paper No. 3554.

[32] Sutherland, Alan (2004) "The Expenditure Switching Effect, Welfare and Monetary Policy in a Small Open Economy" University of St Andrews, unpublished manuscript.

[33] Trefler, Daniel and Huiwen Lai (1999) "The Gains from Trade: Standard errors with the CES Monopolistic Competition Model" University of Toronto, unpublished manuscript. 
Fig 1: Equilibrium degree of price stickiness ( $\alpha=0.003 \phi=7.66$ )

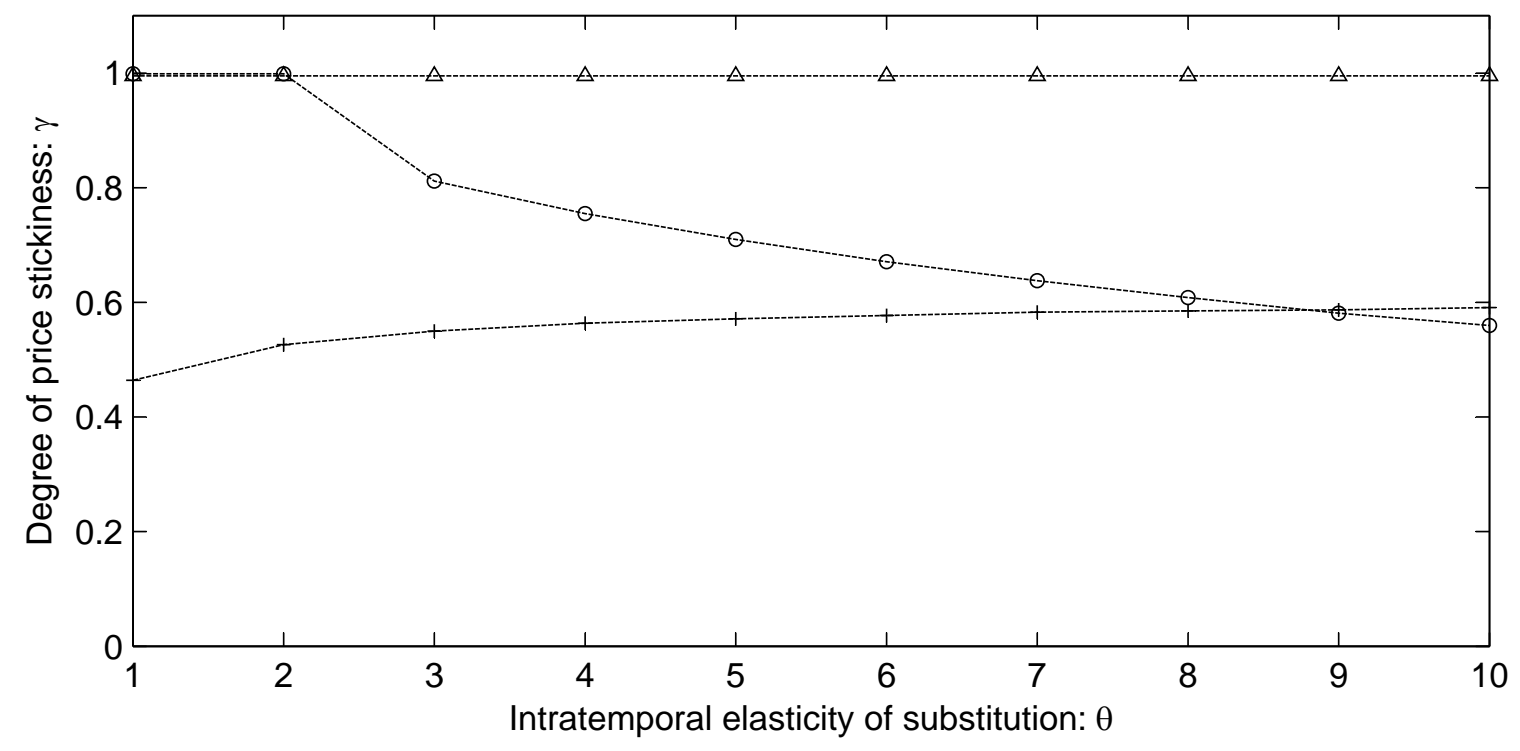

Fixed exchange rate

Money targeting

Inflation targeting 
Fig 2: Welfare $(\alpha=0.003 \phi=7.66)$

(a) Exogenous Price Flexibility

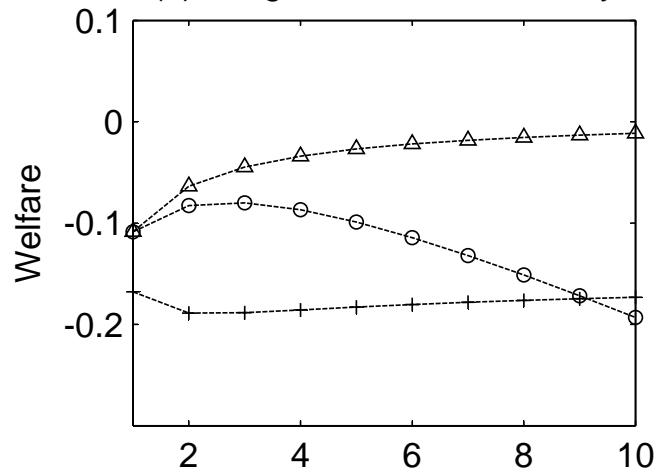

Intratemporal elasticity of substitution: $\theta$ (b) Endogenous Price Flexibility

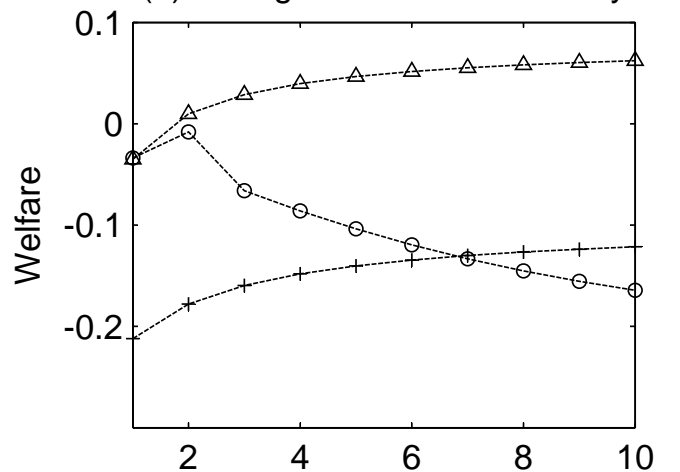

Intratemporal elasticity of substitution: $\theta$

Fig 3: Standard Deviation of Output ( $\alpha=0.003 \phi=7.66)$

(a) Exogenous Price Flexibility

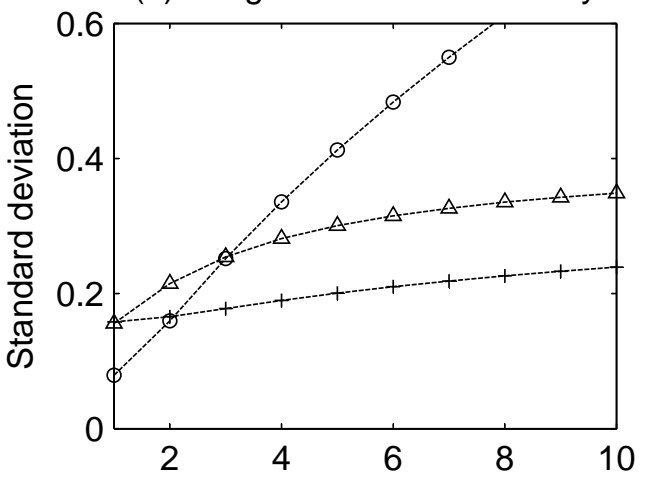

Intratemporal elasticity of substitution: $\theta$ (b) Endogenous Price Flexibility

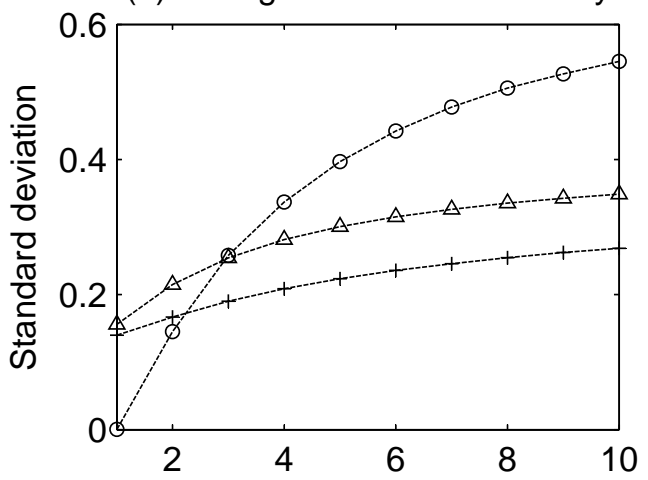

Intratemporal elasticity of substitution: $\theta$

Fig 4: Standard Deviation of the Output Gap ( $\alpha=0.003 \phi=7.66)$

(a) Exogenous Price Flexibility

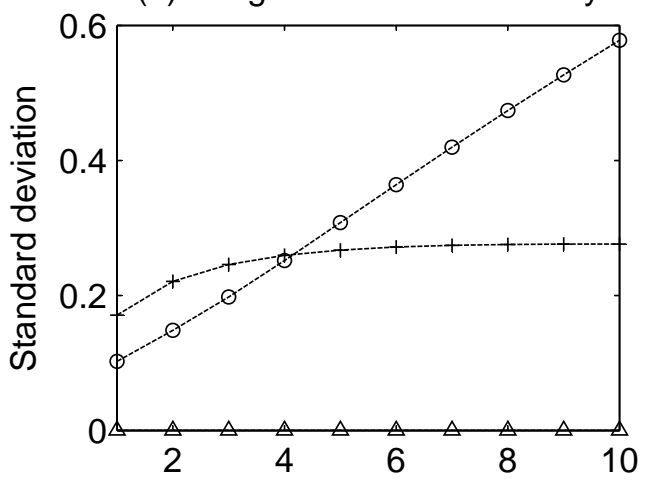

Intratemporal elasticity of substitution: $\theta$ (b) Endogenous Price Flexibility

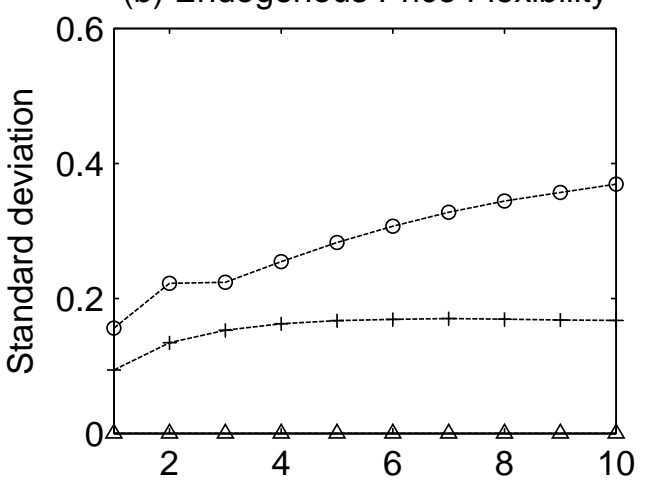

Intratemporal elasticity of substitution: $\theta$ 
Fig 5: Standard Deviation of the Price Gap $(\alpha=0.003 \phi=7.66)$

(a) Exogenous Price Flexibility

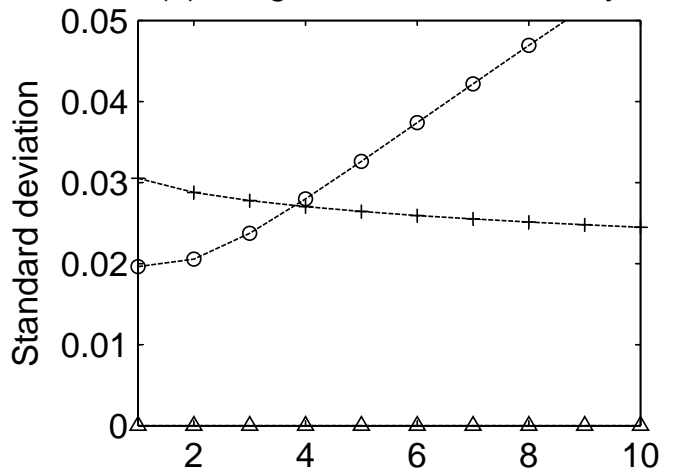

Intratemporal elasticity of substitution: $\theta$ (b) Endogenous Price Flexibility

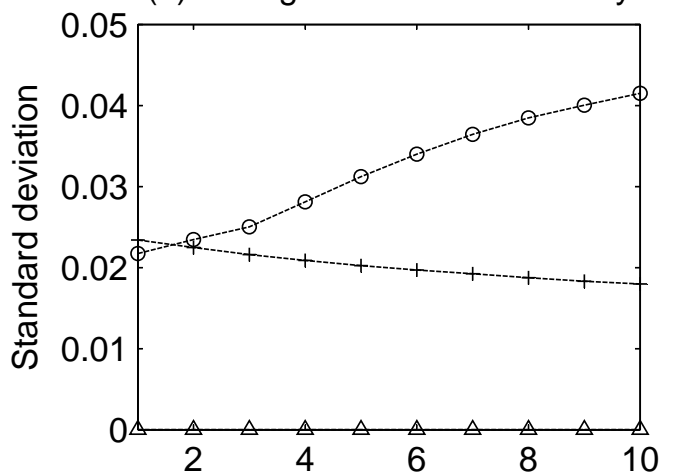

Intratemporal elasticity of substitution: $\theta$

Fig 6: Standard Deviation of the Terms of Trade ( $\alpha=0.003 \phi=7.66)$

(a) Exogenous Price Flexibility

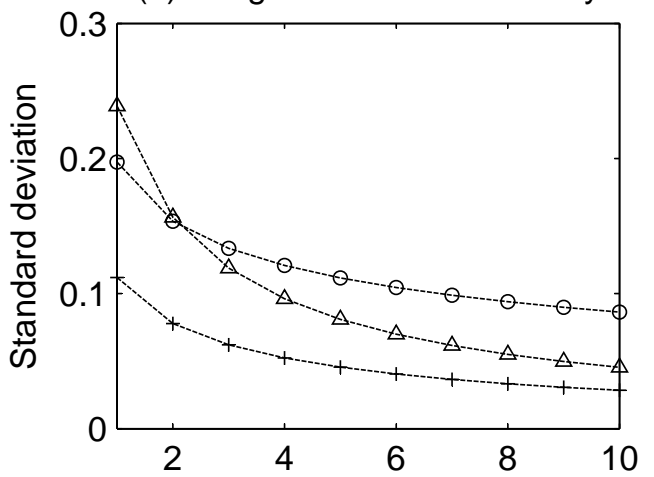

Intratemporal elasticity of substitution: $\theta$ (b) Endogenous Price Flexibility

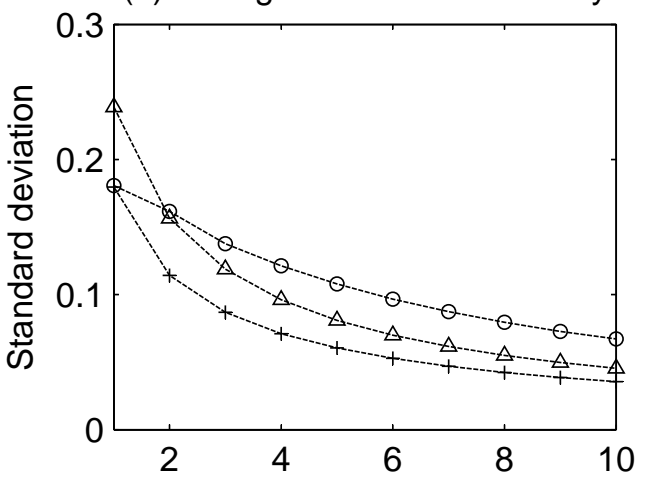

Intratemporal elasticity of substitution: $\theta$

Fig 7: Standard Deviation of Producer Price Inflation ( $\alpha=0.003 \phi=7.66$ )

(a) Exogenous Price Flexibility

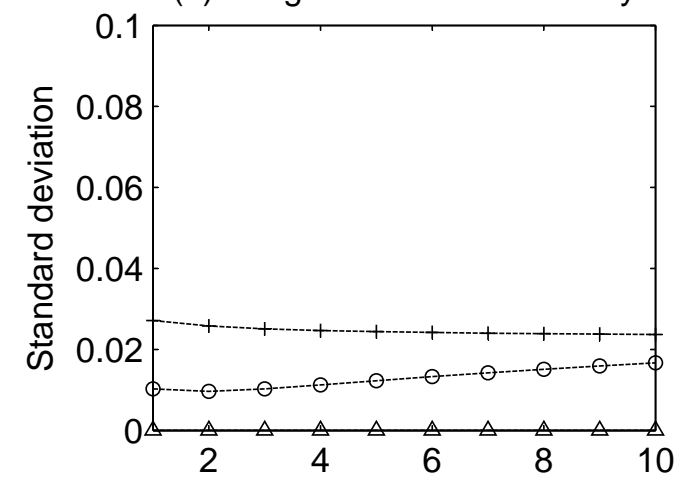

Intratemporal elasticity of substitution: $\theta$ (b) Endogenous Price Flexibility

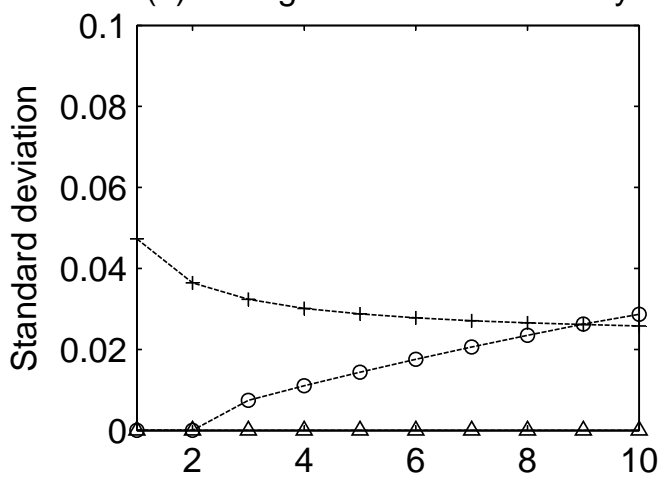

Intratemporal elasticity of substitution: $\theta$ 
Fig 8: Equilibrium degree of price stickiness ( $\alpha=0.004 \phi=7.66)$

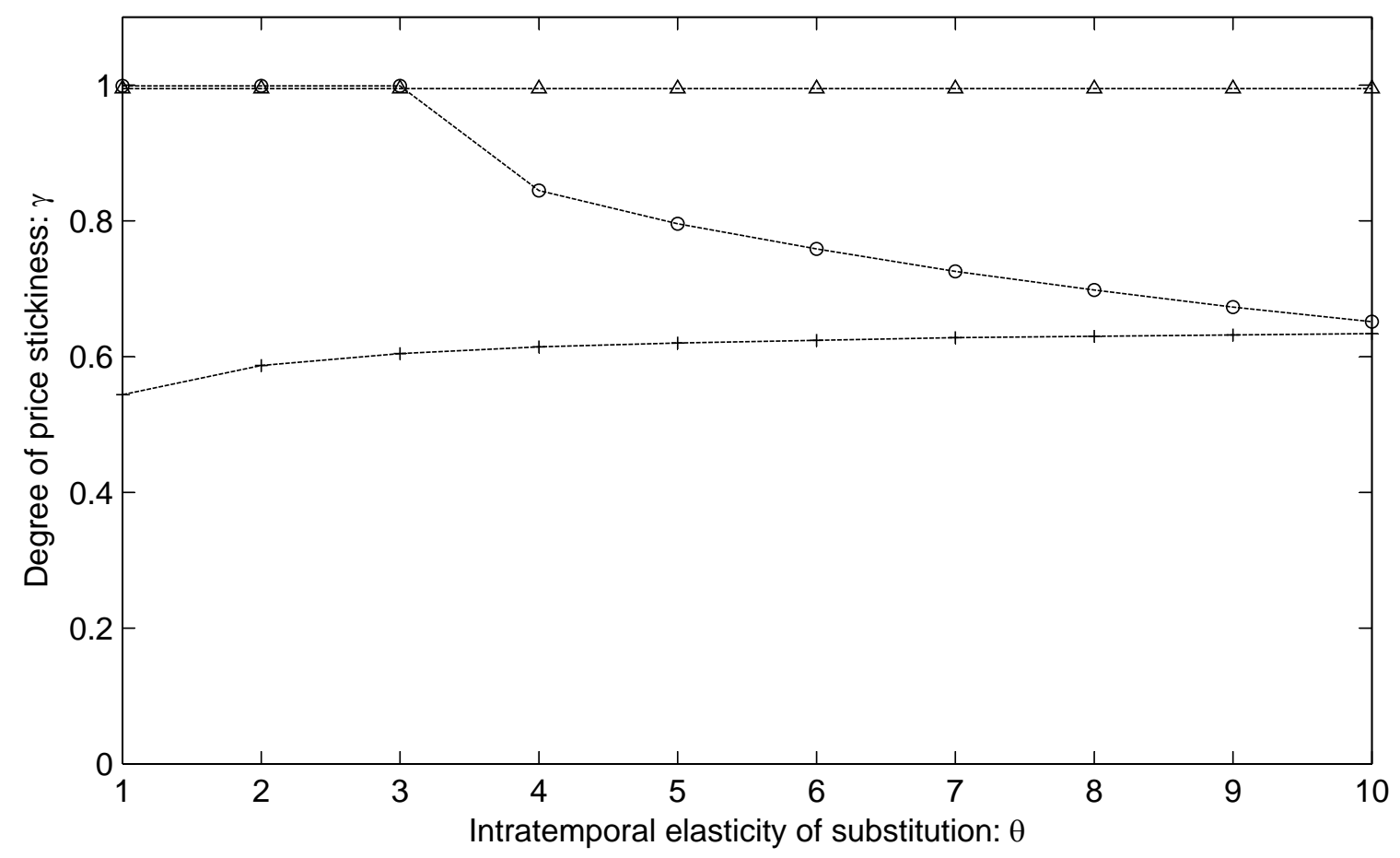

Fig 9: Welfare $(\alpha=0.004 \phi=7.66)$

(a) Exogenous Price Flexibility

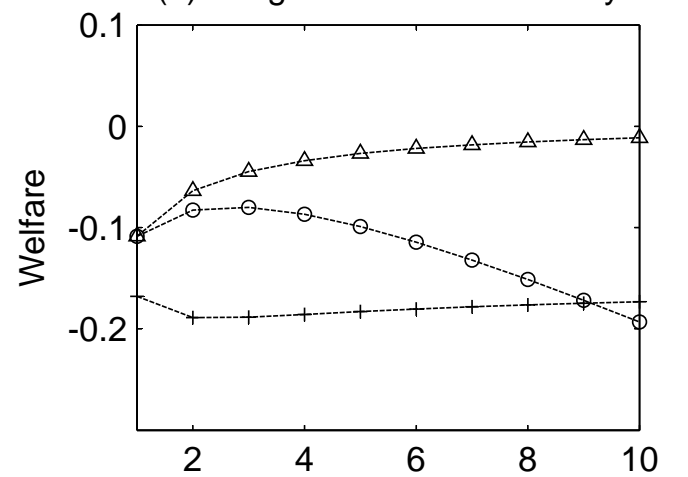

Intratemporal elasticity of substitution: $\theta$ (b) Endogenous Price Flexibility

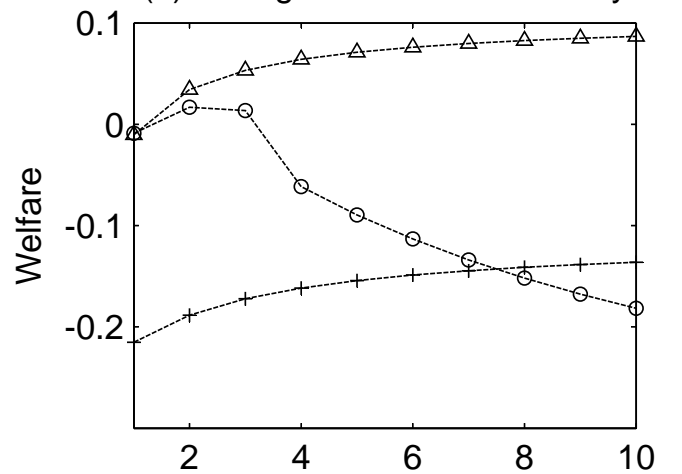

Intratemporal elasticity of substitution: $\theta$ 
Fig 10: Equilibrium degree of price stickiness ( $\alpha=0.003 \phi=4.00$ )

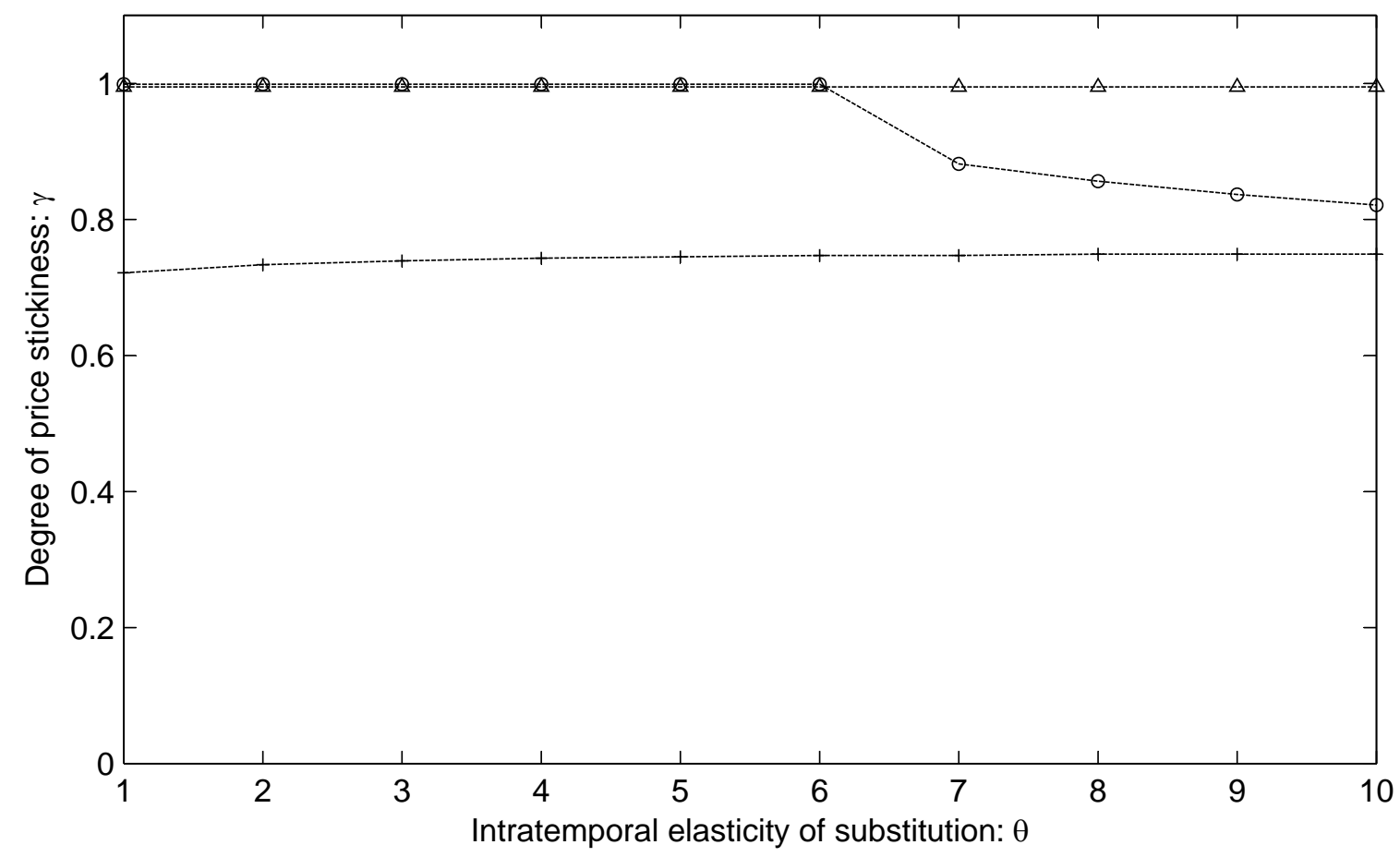

Fig 11: Welfare $(\alpha=0.003 \phi=4.00)$

(a) Exogenous Price Flexibility

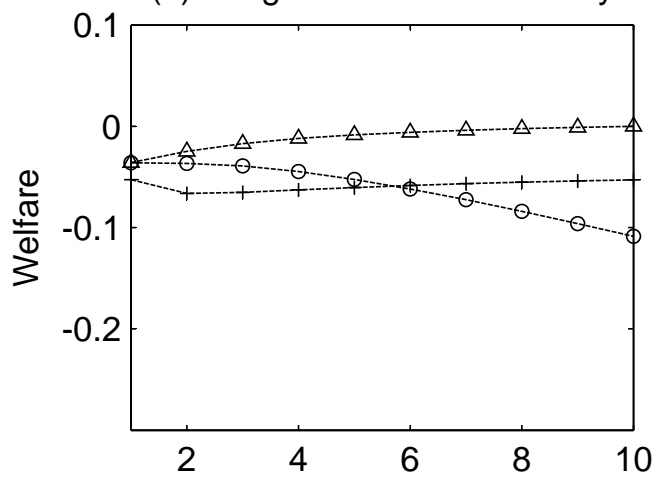

Intratemporal elasticity of substitution: $\theta$ (b) Endogenous Price Flexibility

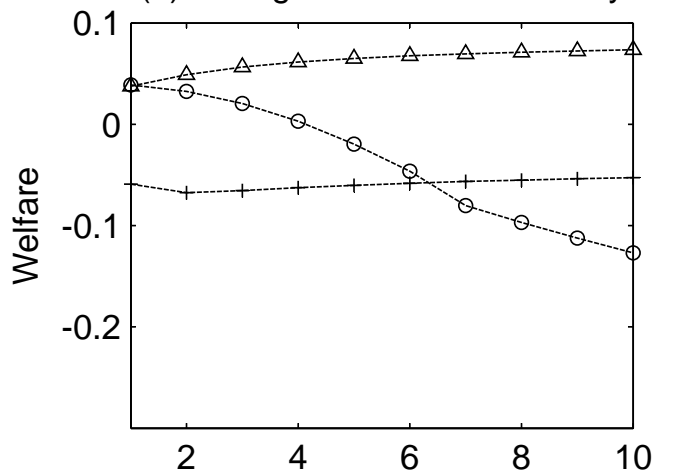

Intratemporal elasticity of substitution: $\theta$ 